\title{
Influence of Graphene Sheet on Microstructure and Properties of Ni-based Alloy Coatings Prepared by Laser Cladding
}

\author{
Geng TIANYUAN, Cunshan WANG*
}

Key Laboratory of Materials Modification by Laser, Ion, and Electron Beams (Dalian University of Technology), Ministry of Education, Dalian 116024, P. R. China

cross $^{\text {ref }}$ http://dx.doi.org/10.5755/j01.ms.25.3.19173

Received 30 September 2017; accepted 07 April 2018

\begin{abstract}
Ni-based alloy cladding layers with different graphene sheet additions were prepared by laser cladding on the $40 \mathrm{CrNi} 2 \mathrm{Si} 2 \mathrm{MoV}$ steel substrate. The influence of the graphene sheet on the microstructure and properties of the cladding layers was investigated. The results show that owing to the diffusion-reaction dissolution, the graphene sheet addition does not bring a corresponding change in the phase constitutions of the cladding layers, i. e., the cladding layers are still composed of $\gamma-\mathrm{Ni}, \mathrm{Ni}_{3} \mathrm{~B}$, and $\mathrm{M}_{7} \mathrm{C}_{3}$ phases. But what has changed is that the solidified structure is refined, and the volume fractions of the eutectic and the carbide are increased with the increase of graphene sheet addition. As a result, the hardness and the wear resistance of the cladding layers gradually increase, whereas the friction coefficient firstly decreases and then increases, with the lowest friction coefficient obtained at 0.5 vol.\% graphene sheet addition. Compared to the Ni-based alloy cladding layers with micro-size graphite additions, the studied cladding layers exhibit improved hardness and wear resistance, good forming quality, and increased friction coefficient.

Keywords: laser cladding, Ni-based alloy, graphene sheet, microstructure, properties.
\end{abstract}

\section{INTRODUCTION}

Laser cladding is an advanced technology that integrates material preparation and surface modification, which shows wide application potentials in the areas of aerospace, automotive, and biomedical science, etc. It is significant to choose and design proper cladding materials in order to obtain laser cladding layers with desired properties and surface quality. Ni-, Co-, and Fe-based alloys are commonly used as laser cladding materials due to their good physicochemical compatibility with steel substrates and high chemical stability [1-4]. However, they can be hardly used in severe abrasion. To solve the problem, some micron-size hard particles had been introduced to form particle-reinforced composites and ceramics had been used to replace the $\mathrm{Ni}-, \mathrm{Co}-$, and $\mathrm{Fe}$ based alloys [5-10]. But these processes introduce cracking and porosity that are not easy to be avoided, especially the cladding of large surfaces. Although a twostep method that has been used to control cracking and porosity, is not practical due to its complicated process and high cost.

The development of nano-materials provides a great opportunity to improve the quality and properties of the composite coatings. Numerous studies demonstrated that by adding appropriate amount of nano-particle (such as $\mathrm{Al}_{2} \mathrm{O}_{3}, \mathrm{CeO}_{2}, \mathrm{Y}_{2} \mathrm{O}_{3}, \mathrm{WC}, \mathrm{TiC}$, and $\mathrm{TiB}$, etc) into laser cladding alloy powders, the coatings presented compact and finer structure, higher mechanical properties, and lower cracking susceptibility in comparison with the traditional coatings $[11-17]$. Graphene sheet - monolayer or multi-layer carbon atoms tightly packed into a twodimensional honeycomb lattice - is predicted to have a

\footnotetext{
* Corresponding author. Tel.: +86-15942816510; fax: +86-411-84708389. E-mail address:laser@dlut.edu.cn (C. Wang)
}

range of unusual properties [18-22]. Its mechanical stiffness may rival the remarkable in-plane values for graphite, and the fracture strength should be comparable to that of carbon nano-tube for similar types of defects, owing to the sp2 hexagonal backbone. One possible route to harnessing graphene sheet would be to incorporate it into various alloys, forming graphene sheet reinforced composites. Here it is worth mentioning that intralayer covalent bonds of graphene sheet are usually much stronger than interlayer crosslinks, thus it is easy for interlayer to slide under the action of shear force to form lubricating transfer films on worn surface as graphite does, which will be beneficial to improve the anti-friction property of material under the conditions of a little oil or free oil lubrication. But the problem is whether the graphene sheet can keep stable during laser cladding and play the intended effect. If not, what impact will it have on the microstructure and properties of the coatings?

In this work, Ni-based alloy coatings with different graphene sheet additions were prepared by laser cladding on the $40 \mathrm{CrNi} 2 \mathrm{Si} 2 \mathrm{MoV}$ steel substrate. The influences of the graphene sheet on the microstructure and properties of the Ni-based alloy coatings were investigated. The stability of the graphene sheets during laser cladding was discussed.

\section{EXPERIMENTAL PROCEDURE}

$40 \mathrm{CrNi} 2 \mathrm{Si} 2 \mathrm{MoV}$ steel with dimension of $20 \mathrm{~mm} \times 10 \mathrm{~mm} \times 10 \mathrm{~mm}$ was chosen as a substrate material. Ni-based alloy powder with a nominal composition of $\mathrm{Ni}_{74.5} \mathrm{Cr}_{13.0} \mathrm{~B}_{3.0} \mathrm{Si}_{4.0} \mathrm{Fe}_{5.0} \mathrm{C}_{0.5}$ (mass percent) was used as host material of laser cladding, to which graphene sheets with the size of $500-800 \mathrm{~nm}$ and layer number of about 10 were added according to the various volume ratios of $0.5 \div 14.0 \%$. The graphene sheets were produced by the direct current arc discharge under 
hydrogen atmosphere (0.07 MPa), using $99.99 \%$ mass purity graphite as the electrodes. The resultant product of graphene sheet powder was collected from the inner wall of the work chamber. The thermal conductivity of the graphene sheet was measured using a LFA447/2 laser flash thermal analyzer. The thermal expansion coefficient was measured by TMA7000 thermo-mechanical analyzer. The Young's modulus and strength was evaluated using a nano Indenter XP with a Berkovich indenter. The detailed results are listed in Table 1 . The powder mixtures were mixed through ball mill, and then pre-placed on the surface of the $40 \mathrm{CrNi} 2 \mathrm{Si} 2 \mathrm{MoV}$ steel to form a $1 \mathrm{~mm}$ thick layer. A $5 \mathrm{~kW}$ continuous wave $\mathrm{CO}_{2}$ laser was used as a heat source to form a single track cladding layer. The optimum parameters were: laser power of $3.0 \mathrm{~kW}$, scanning speed of $3 \mathrm{~mm} / \mathrm{s}$, and laser beam diameter of $5 \mathrm{~mm}$. Argon gas was blown into the melt pool to provide shielding during the laser cladding.

Table 1. Properties of the graphene sheet used in the experiment

\begin{tabular}{|c|c|c|c|}
\hline $\begin{array}{c}\text { Thermal } \\
\text { conductivity, } \\
\mathrm{Wm}^{-1} \mathrm{~K}^{-1}\end{array}$ & $\begin{array}{c}\text { Expansion } \\
\text { coefficient, } \\
\mathrm{K}^{-1}\end{array}$ & $\begin{array}{c}\text { Young's } \\
\text { modulus, TPa }\end{array}$ & Strength,GPa \\
\hline 4900 & $-8.0 \times 10^{-6}$ & 1.0 & 130 \\
\hline
\end{tabular}

Phase identification of these cladding layers was carried out through an XRD-6000 X-ray diffractometer, equipped with a $\mathrm{Ni}$ filtered $\mathrm{Cu} \mathrm{K}_{\alpha}$ radiation operating at $40 \mathrm{kV}$ and $30 \mathrm{~mA}$. The microstructure and composition of these cladding layers were analyzed using a JEOL-5600LV scanning electron microscopy (SEM) and an EPMA-1720 electron probe micro-analyzer (EPMA). Vickers hardness of these cladding layers was measured with a DMH-2LS micro-hardness tester under a load of $0.981 \mathrm{~N}$ and a dwell time of $15 \mathrm{~s}$. The ball-and-disk friction wear tests for all these coatings were performed using a CETR UMT-2 testing machine. A bearing steel ball (GCr15) with a diameter of $5 \mathrm{~mm}$ and a hardness of $55 \mathrm{HRC}$ was selected as the wear couple. The experiment was performed at a normal load of $5 \mathrm{~N}$, a sliding speed of $2 \mathrm{~mm} / \mathrm{s}$, and a wear time of $30 \mathrm{~min}$.

\section{RESULTS AND ANALYSIS}

\subsection{Microstructure}

Fig. 1 shows the X-ray diffraction patterns of the Ni-based alloy cladding layers with different graphene sheet additions. The data show that the microstructure of the cladding layer without graphene sheet addition mostly consists of $\gamma-\mathrm{Ni}, \mathrm{Ni}_{3} \mathrm{~B}$, and $\mathrm{M}_{7} \mathrm{C}_{3}$ phases. When graphene sheet is added into the cladding layers, it does not bring a corresponding change in the phase constitutions of the cladding layers, i. e., the layers are still composed of $\gamma-\mathrm{Ni}$, $\mathrm{Ni}_{3} \mathrm{~B}$, and $\mathrm{M}_{7} \mathrm{C}_{3}$ ( $\mathrm{M}$ stands for $\mathrm{Cr}$ and $\mathrm{Fe}$ elements) phases. The result suggests that the dissolution of the graphene sheet takes place during laser cladding. Here it is worth mentioning that the peaks in $2 \theta$ range of $42-45^{\circ}$ are much smaller for the cladding layers with $0.5-$ vol. $\%$ and 6 vol.\% graphene sheet additions, which may be attributed to the change in growth orientation of the crystalline grains.

Fig. 2 presents a cross-sectional SEM micrograph taken from the coating without graphene sheet addition.

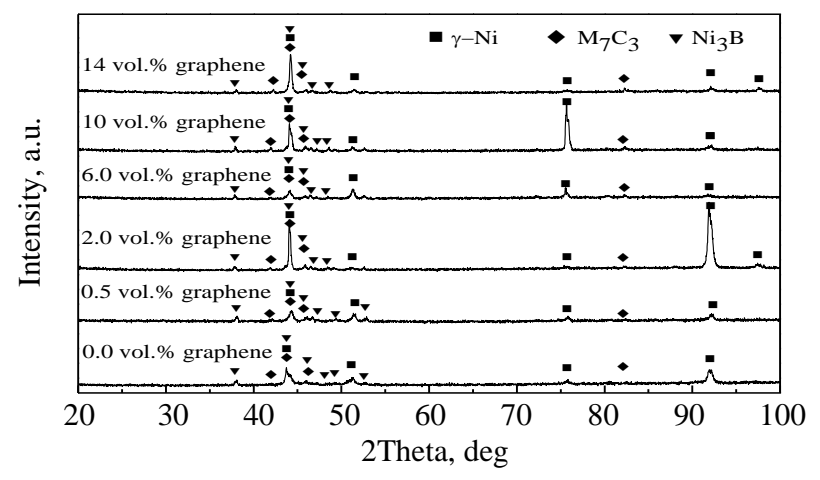

Fig. 1. X-ray diffraction patterns of the Ni-based alloy cladding layers with different graphene sheet additions

According to microstructure difference, the coating can be divided into cladding layer, bonding zone, heatedaffected zone, and substrate. As shown in Fig. 2 a, there are two main structure constituents in the cladding layer: primary dendrites of $\gamma-\mathrm{Ni}$ and eutectic consisting of $\gamma-\mathrm{Ni}$ plus $\mathrm{Ni}_{3} \mathrm{~B}$. Fig. 2 b is a magnified photo of Fig. 2 a, where some particle-like $\mathrm{M}_{7} \mathrm{C}_{3}$ carbides distributed at the eutectic colony boundaries are clearly observed. It is important to note that the primary dendrite is gradually coarsened from the top to the bottom of the cladding layer (Fig. 2 c), as a result of decreased cooling rate and increased temperature gradient. In the cladding zone adjacent to the interface, the coarsened dendrite exhibits epitaxial growth characters (Fig. 2 d), because the heat flows out of the cladding zone towards the substrate material. The interface is where the laser melts the surface of the substrate, onto which the material is cladded. This makes the microstructure of the interface different from that of the cladding layer, a planar crystal with a thickness of about $7 \mu \mathrm{m}$ is formed as shown in Fig. 2 d. The heat-affected zone in the substrate closing to the interface undergoes a transformation of original temper sorbite into austenite at higher temperature. On a subsequent cooling process, a martensitic structure is formed (Fig. 2 e).

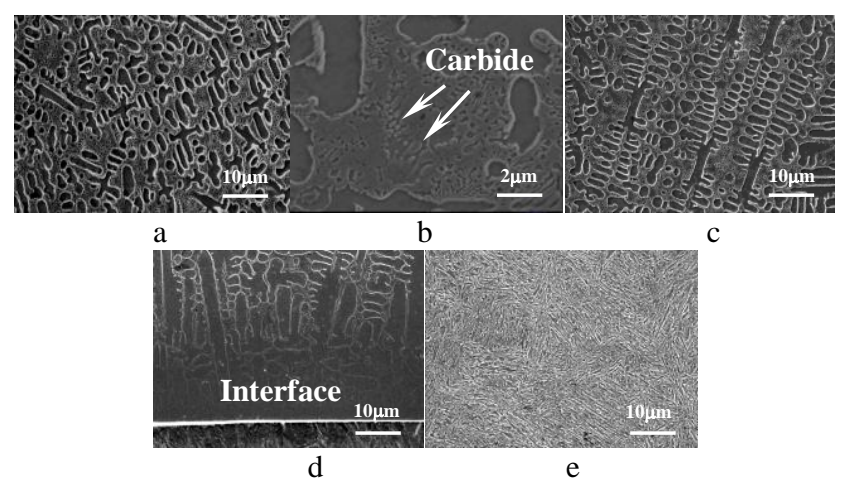

Fig. 2. Cross-section morphology of the Ni-based alloy cladding layer without graphene addition: a-surface of cladding layer; $b$-magnified photo of Fig. $2 \mathrm{a}$; $\mathrm{c}$-middle zone of cladding layer; $\mathrm{d}$-interface bonding zone; $\mathrm{e}$-heataffected zone

The typical SEM micrographs of the Ni-based cladding layers with different graphene sheet additions are shown in Fig. 3. These cladding layers present similar microstructure characteristic to the cladding layer without 
graphene sheet addition, i.e., their major structures are still composed of $\gamma-\mathrm{Ni}$ dendrites and $\left(\gamma-\mathrm{Ni}+\mathrm{Ni}_{3} \mathrm{~B}\right)$ eutectic as shown in Fig. $3 \mathrm{a}-\mathrm{e}$. The difference is that the primary dendrite is gradually refined with the increase of graphene sheet addition, whose average secondary arm spacing is $2.7 \mu \mathrm{m}, 2.6 \mu \mathrm{m}, 1.9 \mu \mathrm{m}, 1.5 \mu \mathrm{m}$, and $1.3 \mu \mathrm{m}$ as the addition of graphene sheet increases from 0.5 vol. $\%$ to $14.0 \mathrm{vol} . \%$, smaller than that $(2.9 \mu \mathrm{m})$ of the cladding layer without graphene sheet addition. Meanwhile, the volume fraction of eutectic changes from $44.1 \%$ to $45.4 \%, 49.9 \%$, $51.5 \%$, and $55.8 \%$ (Fig. $3 \mathrm{a}-\mathrm{e}$ ), higher than that $(42.9 \%$ ) in the cladding layer without graphene addition. The fact may be connected with the formation of carbide at high temperature. Owing to the nanometer scale and high absorptivity to laser, surface atoms on graphene sheet possess high activity, and thus easily react with surrounding melts to form $\mathrm{M}_{7} \mathrm{C}_{3}$ carbides. EPMA analysis reveals that $\mathrm{Ni}$ has a limited solid solubility in the $\mathrm{M}_{7} \mathrm{C}_{3}$ carbide, the more the graphene sheet addition is, the more the amount of $\mathrm{Ni}$ dissolved in the carbide as shown in Table 2. This leads to the composition of the remaining liquid phase offset gradually toward the eutectic composition. As a result, the increased graphene sheet addition not only increases the volume fraction of the eutectic, but also improves the super-cooling degree of the liquid phase, resulting in refined solidified structure.

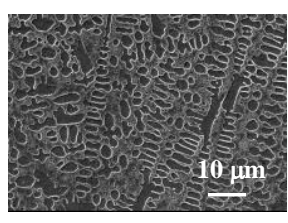

a

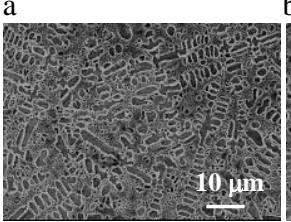

d

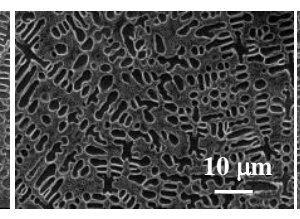

$\mathrm{b}$

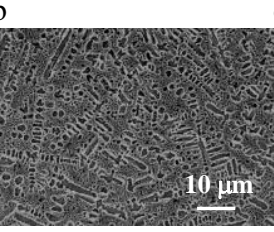

Fig. 3. Typical microstructure of the cladding layers with different graphene sheet additions: $a-0.5$ vol. $\%$ graphene sheet; b-2.0 vol.\% graphene sheet; $\mathrm{c}-6.0$ vol.\% graphene sheet; $\mathrm{d}-10.0 \mathrm{vol} \%$ graphene sheet; $\mathrm{e}-14.0$ vol. $\%$ graphene sheet

Table 2. The chemical composition of $\mathrm{M}_{7} \mathrm{C}_{3}$ carbides in the cladding layers with different graphene sheet addition

\begin{tabular}{|c|c|c|c|c|}
\hline \multirow{2}{*}{$\begin{array}{c}\text { Graphene sheet } \\
\text { content, vol. \% }\end{array}$} & \multicolumn{4}{|c|}{ Composition, at. \% } \\
\cline { 2 - 5 } & $\mathrm{Cr}$ & $\mathrm{Fe}$ & $\mathrm{Ni}$ & $\mathrm{C}$ \\
\hline 0.5 & - & - & - & - \\
\hline 2.0 & 64.8 & 9.7 & 3.2 & 22.3 \\
\hline 6 & 62.1 & 10.1 & 4.3 & 23.5 \\
\hline 10 & 59.4 & 9.8 & 4.9 & 25.9 \\
\hline 14 & 56.9 & 10.2 & 5.8 & 27.1 \\
\hline
\end{tabular}

* It is impossible to measure exactly the compositions of $\mathrm{M}_{7} \mathrm{C}_{3}$ in the caldding layer with 0.5 vol. $\%$ graphene sheet addition using EPMA, because the size of the carbide is less than $1 \mu \mathrm{m}$.

Another important difference is the changes in the size, number, and distribution of the carbides. Fig. 4 shows the SEM backscattered electron images of the Ni-based cladding layers with different graphene sheet additions. The dark carbide particles are clearly observed as they contain low-atomic-number of carbon element. It is found from Fig. 4 that the carbide particles show an increasing trend in size with the increase of graphene sheet addition. The value is measured to be $1.1 \mu \mathrm{m}, 1.4 \mu \mathrm{m}, 2.3 \mu \mathrm{m}$, $3.2 \mu \mathrm{m}$, and $4.9 \mu \mathrm{m}$, respec-tively. This may be associated with the agglomeration of the graphene sheet. When the graphene sheets are dispersed in the melts, they will collide with each other under the convection of the melts, and recombine together to form agglomerates. In the agglomerates, the graphene sheets can be associated with one another through chemical bonds and physical attraction forces at interfaces. Once formed, the agglomerates are very difficult to destroy. The more the graphene sheets are added, the greater the agglomerating tendency is, and the larger the carbide is. Meanwhile, the number of the carbides is increased from $0.72 \%$ to $1.76 \%$, $2.98 \%, 8.11 \%$, and $23.12 \%$.

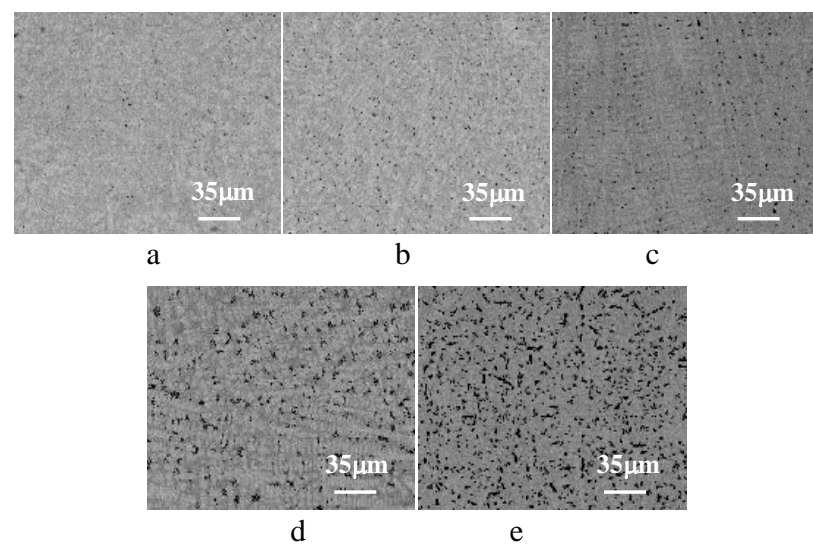

Fig. 4. Back scattered electron images of the cladding layers with different graphene sheet additions: $\mathrm{a}-0.5 \mathrm{vol} . \%$ graphene sheet; $\mathrm{b}-2.0$ vol.\% graphene sheet; $\mathrm{c}-6.0$ vol.\% graphene sheet; $\mathrm{d}-10.0 \mathrm{vol} \%$ graphene sheet; $\mathrm{e}-14.0$ vol. $\%$ graphene sheet

It is also observed from Fig. 4 that the increased graphene sheet addition makes carbides distribute more uniformly. Based on grid-counting method, the distribution uniformity of the carbides is measured to be $75.8 \%$, $83.0 \%, 88.1 \%, 91.3 \%$, and $94.7 \%$ at $0.50 \div 14.0$ vol. $\%$ graph-ene additions, respectively. The change is mainly related to the movement of the graphene sheet in molten pool. Owing to low density, the graphene sheet would ascend in the molten pool while being confined by convection. With the increasing of graphene sheet addition, the probability of collision among the graphene sheets increases. This will decrease the ascending rate of the graphene sheet, being beneficial to a uniform distribution of its reaction product. In addition, the interaction between the carbide and the liquid-solid interface also plays a key role in determining the distribution of the carbides, especially the micro-distribution of the carbide. Unlike the cladding layer without the graphene sheet addition, the carbide is located at the boundary of the primary dendrites, indicating that the carbide is pushed away by the liquidsolid interface, which is also beneficial to a uniform distribution of carbides. 


\subsection{Dilution rate}

Dilution rate, as an important factor influencing the properties of cladding layer, is defined as the ratio of cladding depth $(D)$ to the sum of cladding height $(H)$ and cladding depth $(D)$, namely, $d=D /(D+H)$. Fig. 5 show the dilution rates of the cladding layers obtained from the above equation. It can be seen that dilution rate gradually decreases with the increasing of graphene sheet addition. This is mainly concerned with the following facts: the energy transferred to the substrate is mainly through heat conduction in the process of presetting powder laser cladding. Owing to high thermal conductivity of graphene sheet, the increased graphene sheet addition increases the energy transferred to the substrate, leading to the increased extent of melting of the substrate. But meanwhile, it decreases the temperature gradient of molten pool, and increases the viscosity of the melt. This will reduce convection intensity of the melt, resulting in lower mixing of the substrate and clad material. As a result, the dilution rate decreases with the increase of graphene sheet addition.

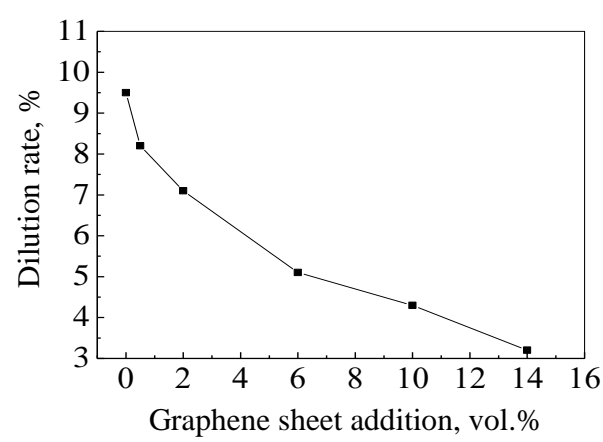

Fig. 5. Influence of graphene sheet on the dilution rate of the cladding layers

\subsection{Microhardness}

Fig. 6 shows the microhardness plots along the crosssection of the coatings with different graphene sheet additions. It is clear that there are three plateaus in each micro-hardness curve, corresponding to the cladding layer, heat-affected zone and substrate, respectively.

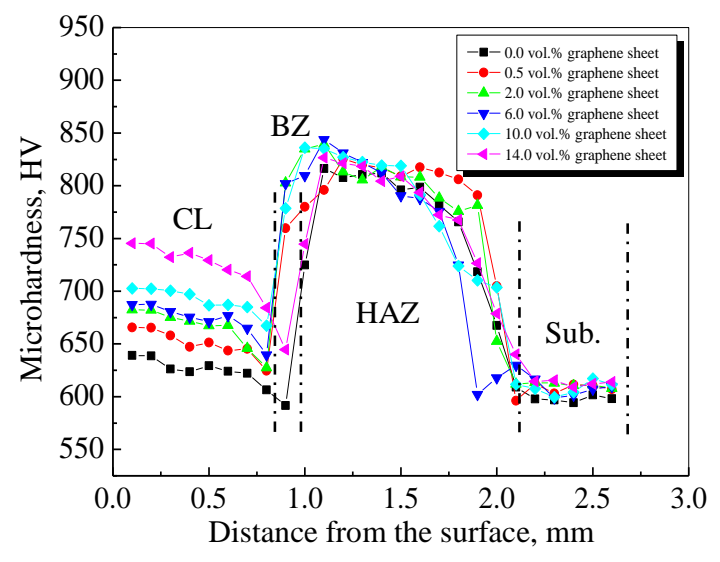

Fig. 6. Microhardness plots along the cross-section of the coatings with different graphene sheet additions
As men-tioned above, the microstructure of the cladding layers is coarsened gradually along the layer depth direction (for example, the microstructure changes from Fig. 2 a to Fig. 2 c to Fig. 2 d), which results in gradually decreased hardness. The trend is maintained till the interface bonding zone due to the formation of the planar crystal (such as the interface zone shown in Fig. 2 d). Then a steep hardness increase occurs in the heat-affected zone, which is a result from the formation of martensitic structure as shown in Fig. 2 e. However, the hardness sharply falls again further awayfrom the surface, and reaches the minimum in the substrate, because the microstructure changes gradually from martensite to original temper sorbite. It can also be found from Fig. 6 that the average hardness of the cladding layers gradually increases with the increasing of graphene sheet addition, as a result of grain refinement, as well as increases of volume fractions of the eutectic and the carbide.

\subsection{Tribological properties}

Fig. 7 displays curves of friction coefficient and wear volume of the cladding layers with graphene sheet added amount, in which the circle and square symbols represent friction coefficient and wear volume, respectively. It can be found that the friction coefficient decreases with the graphene sheet addition up to 0.5 vol. $\%$, and then a sharp increase occurs with further graphene sheet addition. This result suggests that the cladding layer with 0.5 vol.\% graphene sheet addition has the best anti-friction property. Unlike friction coefficient, the wear volume decreases gradually with the increasing of the graphene sheet addition, indicating that increased graphene sheet addition will improve the wear resistance of the cladding layers.

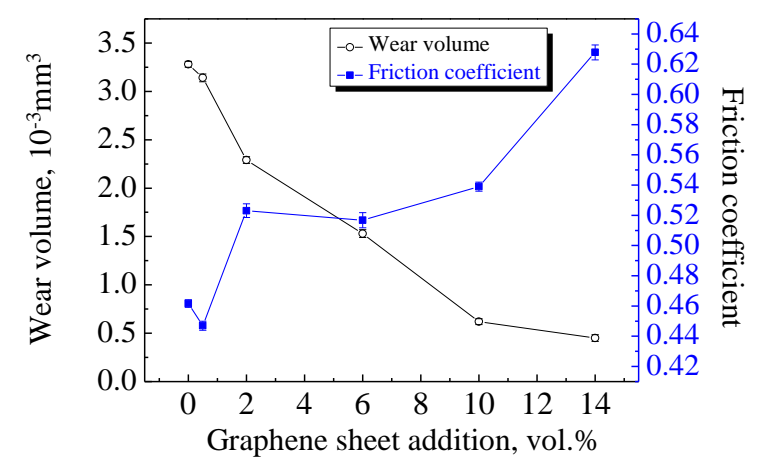

Fig. 7. Influence of graphene sheet on the friction coefficient and wear volume of the cladding layers

In order to investigate the mechanism underlying the above changes, the worn surface morphologies of the cladding layers were observed by SEM. As shown in Fig. 8 a, besides the furrows characterizing abrasive wear, fatigue spalling pits appear on the worn surface of the cladding layer without graphene sheet addition. When 0.5 vol. \% graphene sheet is added to the cladding layer, the furrows begins to become narrower in width and shallower in depth, and the spalling pits is less and becomes smaller in size (Fig. 8 b), because increasing hardness not only improves the anti-abrasive wear ability of the cladding layer, but also inhibits the initiation of the fatigue cracks to some extent. This explains why the tribological properties 
of the cladding layer with 0.5 vol. $\%$ graphene sheet addition are better than those without graphene sheet addition. With even more graphene sheet addition, the spalling pits disappear, and the furrows become narrower in width and shallower in depth even more. But some adhesive substances begin to appear on the worn surfaces of the coatings (Fig. $8 \mathrm{c}-\mathrm{f}$ ). EPMA analysis reveals that the adhesive substances are mainly composed of $\mathrm{Fe}$ and $\mathrm{Cr}$ elements. This result indicates that material transfer from the GCr15 steel ball occurs during the wear process. The higher the hardness of the cladding layer, the more the material transfers from GCr15 steel ball. Therefore, the wear resistance of the cladding layers gradually increases with the increasing graphene sheet addition from 2.0 to 14.0 vol. $\%$, whereas the anti-friction property decreases.

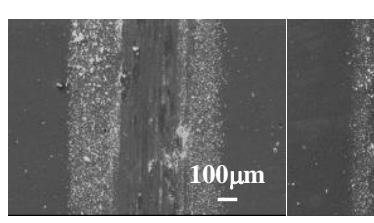

$\mathrm{a}$

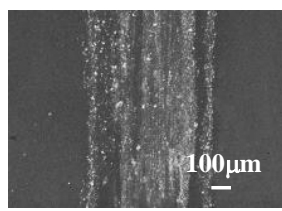

d

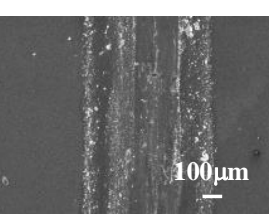

c

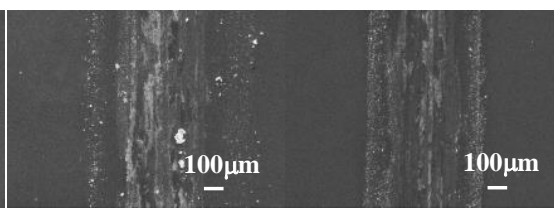

e

f
Fig. 8. Worn morphologies of the cladding layers with different graphene sheet additions: a -0.0 vol. $\%$ graphene sheet; $\mathrm{b}-0.5$ vol.\% graphene sheet; $\mathrm{c}-2.0$ vol.\% graphene sheet $\mathrm{d}-6.0$ vol.\% graphene sheet; $\mathrm{e}-10.0$ vol.\% graphene sheet; f 14.0 vol.\% graphene sheet

\section{DISCUSSION}

During non-equilibrium solidification process of laser cladding, the dissolution behavior of graphene sheet is very complicated, in which several different mechanisms of dissolution may be involved. As mentioned above, an important mechanism is that graphene sheet is dissolved through diffusion-reaction. Graphene sheet has good structural stability at ordinary temperature due to strong inter-atomic bonds. However, it will become thermodynamically unstable or metastable under high power laser. This provides favorable conditions for reaction of graphene sheet with surrounding melts to form $\mathrm{M}_{7} \mathrm{C}_{3}$ carbides. At $1200{ }^{\circ} \mathrm{C}$ that is slightly higher than the melting point of the Ni-based alloy, $\mathrm{M}_{7} \mathrm{C}_{3}$ carbide has negative formation energy $\left(-50.60 \mathrm{~kJ} \cdot \mathrm{mol}^{-1}\right)$, and the reaction process can occur spontaneously. Therefore, graphene sheet, as a reactant, will be dissolved gradually with the reaction process.

Previous research has shown that when the micro-size (about 65-100 $\mu \mathrm{m}$ in diameter) graphite was added to the Ni-based alloy cladding layers, they underwent a similar dissolution process during laser cladding process [23]. But unlike graphene sheet addition, the residual graphite was clearly observed as the addition of graphite was 6.0 vol.\%, and exhibited increasing trend in size and number with the even more graphite addition (Fig. 9). Due to the difference in solubility of graphite and graphene sheet, the cladding layers with graphene sheet addition have higher fraction carbides than those with equivalent graphite additions. Meanwhile, the formers show more uniform carbide distribution than the latter. The volume fraction and distribution uniformity of the carbides in the cladding layers with different graphite additions are listed in Table 3.

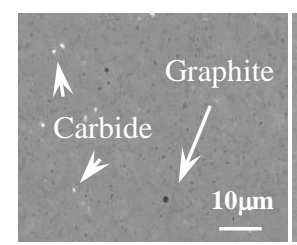

a

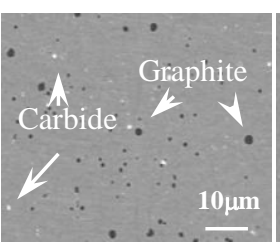

b

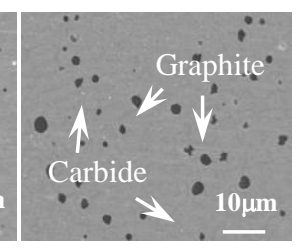

c
Fig. 9. SEM images of the layers with different graphite additions: a -6.0 vol. $\%$ graphite; $\quad b-10.0$ vol. $\%$ graphite; c- 14.0 vol.\% graphite

Fig. 10 presents the typical SEM micrographs of the cladding layers with different graphite additions. The cladding layers had very similar microstructure to those with equivalent graphene sheet additions, just with slight difference in the size of dendrite and the volume fraction of eutectic phase. By comparing the data in Table 3 and in section 3.1, it can be found that the cladding layers with graphene sheet additions have slightly finer microstructure and slightly higher fraction of eutectic than those with equivalent graphite additions on the whole.

Table 3. Microstructure parameters of the cladding layers with different graphite additions

\begin{tabular}{|c|c|c|c|c|}
\hline $\begin{array}{c}\text { Graphite } \\
\text { content, } \\
\text { vol. } \%\end{array}$ & $\begin{array}{c}\text { Carbide } \\
\text { number, } \\
\text { vol. } \%\end{array}$ & $\begin{array}{c}\text { Carbide } \\
\text { distribution } \\
\text { uniformity, } \%\end{array}$ & $\begin{array}{c}\text { Secondary } \\
\text { arm spacing, } \\
\mu \mathrm{m}\end{array}$ & $\begin{array}{c}\text { Eutectic } \\
\text { number, } \\
\text { vol.\% }\end{array}$ \\
\hline 0.5 & -- & - & 2.9 & 43.7 \\
\hline 2.0 & - & - & 2.7 & 45.0 \\
\hline 6.0 & 0.67 & 71.3 & 2.0 & 49.4 \\
\hline 10.0 & 1.43 & 84.5 & 1.8 & 52.3 \\
\hline 14.0 & 1.42 & 86.2 & 1.5 & 55.2 \\
\hline
\end{tabular}

* The lack of the date at graphite addition below 6.0 vol.\% resulted from the fact that no obvious carbides were observed

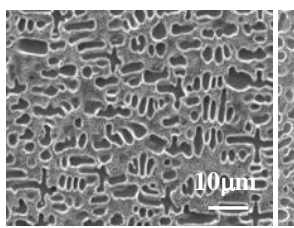

a

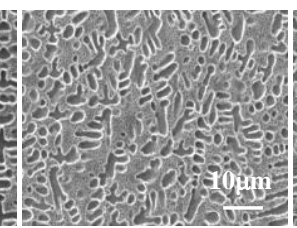

b

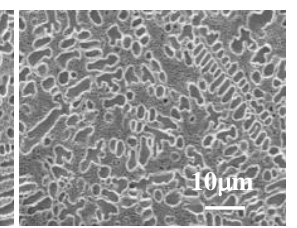

c

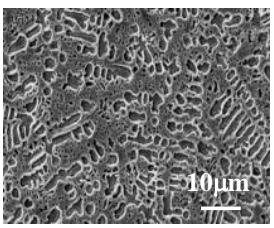

d

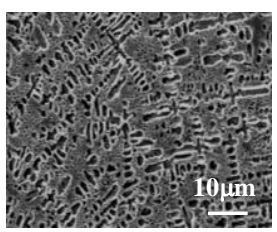

Fig. 10. The microstructure of the cladding layers with different graphite additions: $\mathrm{a}-0.5$ vol. $\%$ graphite; $\mathrm{b}-2.0$ vol. $\%$ graphite; c-6.0 vol.\% graphite; $\mathrm{d}-10.0$ vol.\% graphite; $\mathrm{e}-14.0 \mathrm{vol} . \%$ graphite

Owing to the above microstructure differences, the cladding layers with graphene sheet additions present improved hardness compared to those with equivalent graphite additions. The high hardness, in turn, improves 
the anti-abrasiveness and the anti-fatigue wear, leading to an enhanced wear resistance compared with the latter. On the contrary, the former has reduced anti-friction property, especially at high graphene sheet additions, because material transfer from the GCr15 steel ball occurs during the wear process as shown in Fig. $8 \mathrm{c}-\mathrm{f}$, and the dissolution of graphene sheet loses its action of self lubrication. This differs from the cladding layers with high fraction graphite additions, only abrasive wear took place on their worn surfaces and the residual graphites had an action of self lubrication (figure not shown). The properties of the cladding layers with different graphite additions are listed in Table 4.

Table 4. Properties of the cladding layers with different graphite additions

\begin{tabular}{|c|c|c|c|}
\hline $\begin{array}{c}\text { Graphite } \\
\text { content, vol.\% }\end{array}$ & Hardness, HV & $\begin{array}{c}\text { Wear volume, } \\
10^{-3} \mathrm{~mm}^{3}\end{array}$ & $\begin{array}{c}\text { Friction } \\
\text { coefficient }\end{array}$ \\
\hline 0.5 & 600 & 4.2 & 0.465 \\
\hline 2.0 & 625 & 3.7 & 0.470 \\
\hline 6.0 & 653 & 3.0 & 0.461 \\
\hline 10.0 & 675 & 2.1 & 0.415 \\
\hline 14.0 & 695 & 1.9 & 0.409 \\
\hline
\end{tabular}

Here it is worth mentioning that the studied cladding layers exhibit also high forming quality. Although the carbides formed through the dissolution of graphene sheet are up to micro-scale, their distributions are relatively more uniform in comparison with the micro-size graphite additions. This will release the local stress concentration to some extent. As a result, no cracks are formed as the graphene sheet addition reaches to 14.0 vol.\%, whereas some cracks were clearly observed when the addition of graphite was more than 6.0 vol.\% (figure not shown), mainly resulting from the existence of the residual graphites which acted as crack initiation sites.

\section{CONCLUSIONS}

Ni-based alloy coatings with different graphene sheet additions were prepared by laser cladding on the $40 \mathrm{CrNi} 2 \mathrm{Si} 2 \mathrm{MoV}$ steel substrate. The influences of the graphene sheet on the microstructure and properties of the Ni-based alloy coatings were investigated. The main results are summarized as follows:

1. Ni-based alloy cladding layers with different graphene sheet additions mostly consist of $\gamma-\mathrm{Ni}, \mathrm{Ni}_{3} \mathrm{~B}$, and $\mathrm{M}_{7} \mathrm{C}_{3}$ phases. With the increase of the graphene sheet addition, the solidified structure is refined, and the volume fractions of the eutectic and the carbide are increased.

2. The main dissolution mechanism of graphene sheet is diffusion-reaction dissolution during laser cladding.

3. With the increasing of graphene sheet addition, the dilution rate of the cladding layers gradually decreases, the hardness and the wear resistance change in the opposite trend, while the the anti-friction property firstly increases and then decreases, with the best anti-friction property obtained at 0.5 vol.\% graphene sheet addition. In comparison to the cladding layers with equivalent graphite additions, the studied cladding layers show high hardness, improved wear resistance, good forming quality, but have increased friction coefficient.

\section{Acknowledgments}

This work was supported by Aviation Industry Corporation of China.

\section{REFERENCES}

1. Zeisig, J., Schädlich, N., Giebeler, L., Sander, J., Eckert, J., Kühn, U. Microstructure and Abrasive Wear Behavior of a Novel FeCrMoVC Laser Cladding Alloy for High-performance Tool Steels Wear 382-383 2017: pp. $107-112$. https://dx. doi.org/10.1016/j.wear.2017.04.021

2. Xu, X., Mi, G.Y., Chen, L., Xiong, L.D., Jiang, P., Shao, X.Y., Wang, C.M. Research on Microstructures and Properties of Inconel 625 Coatings Obtained by Laser Cladding with Wire Journal of Alloys and Compounds 715 2017: pp. $362-373$. https://dx. doi.org/10.1016/j.jallcom.2017.04.252

3. Qin, R.Y., Zhang, X.J., Guo, S.Q., Sun, B.B., Tang, S.Y., Li, W.Q. Laser Cladding of High Co-Ni Secondary Hardening Steel on 18Cr2Ni4WA Steel Surface \& Coatings Technology 285 2016: pp. 242-248. https://dx. doi.org/10.1016/j.surfcoat.2015.11.032

4. Ansari, M., Razavi, R.S., Barekat, M. An Empiricalstatistical Model for Coaxial Laser Cladding of NiCrAlY Powder on Inconel 738 Superalloy Optics \& Laser Technology 86 2016: pp. 136-144.

https://dx. doi.org/10.1016/j.optlastec.2016.06.014

5. Muvvala, G., Karmakar, D.P., Nath, A.K. Online Assessment of TiC Decomposition in Laser Cladding of Metal Matrix Composite Coating Materials and Design 121 2017: pp. $310-320$. https://dx. doi.org/10.1016/j.matdes.2017.02.061

6. Zhang, H., Zou, Y., Zou, Z.D., Wu, D.T. Microstructure and Properties of Fe-based Composite Coating by Laser Cladding Fe-Ti-V-Cr-C-CeO 2 Powder Optics \& Laser Technology 65 2015: pp. 119-125.

https://dx. doi.org/10.1016/j. optlastec.2014.06.016

7. Bartkowski, D., Bartkowsk, A. Wear Resistance in the Soil of Stellite-6/WC Coatings Produced Using Laser Cladding Method International Journal of Refractory Metals and Hard Materials 64 2017: pp. 20-26.

https://dx. doi.org/10.1016/j. ijrmhm.2016.12.013

8. Ding, L., Hu, S.S., Quan, X.M., Shen, J.R. Effect of Aging Treatment on Microstructure and Properties of VN Alloy Reinforced Co-based Composite Coatings by Laser Cladding Materials Characterization 129 2017: pp. 8087.

https://dx. doi.org/10.1016/j. matchar.2014.04.030

9. Cai, Y.C., Luo, Z., Feng, M.N., Liu, Z.M., Huang, Z.Y., Zeng, Y.D. The Effect of $\mathrm{TiC} / \mathrm{Al}_{2} \mathrm{O}_{3}$ Composite Ceramic Reinforcement on Tribological Behavior of Laser Cladding Ni60 Alloys Coatings Surface \& Coatings Technology 291 2016: pp. 222-229.

https://dx. doi.org/10.1016/j. surfcoat.2016.02.033

10. Bartkowski, D., Mlynarczak, A., Piasecki, A., Dudziak, B., Gościański, M., $\quad$ Bartkowska, A. Microstructure, Microhardness and Corrosion Resistance of Stellite-6 Coatings Reinforced with WC Particles Using Laser Cladding Optics \& Laser Technology 68 2015: pp. $191-201$.

https://dx. doi.org/10.1016/j. optlastec.2014.12.055 
11. Bi, G., Sun, C.N., Nai, M.L., Wei, J. Micro-structure and Mechanical Properties of Nano-TiC Reinforced Inconel 625 Deposited Using LAAM Physics Procedia 41 2013: pp. $828-834$.

https://dx. doi.org/10.1016/j. phpro.2013.03.155

12. Duan, X.X., Gao, S.Y., Dong, Q., Zhou, Y.F., Xi, M.Z., Xian, X.P., Wang, B. Reinforcement Mechanism and Wear Resistance of $\mathrm{Al}_{2} \mathrm{O}_{3} / \mathrm{Fe}-\mathrm{Cr}-\mathrm{Mo}$ Steel Composite Coating Produced by Laser Cladding Surface \& Coatings Technology 291 2016: pp. 230-238.

https://dx. doi.org/10.1016/j. surfcoat.2016.02.045

13. Dua, B.S., Paital, S.R., Dahotre, N.B. Synthesis of $\mathrm{TiB}_{2}-$ $\mathrm{TiC} / \mathrm{Fe}$ Nano-composite Coating by Laser Surface Engineering Optics \& Laser Technology 45 2013: pp. $647-653$ https://dx. doi.org/10.1016/j.optlastec.2012.05.017

14. Farahmand, P., Liu, S., Zhang, Z., Kovacevic, R. Laser Cladding Assisted by Induction Heating of $\mathrm{Ni}-\mathrm{WC}$ Composite Enhanced by Nano-WC and $\mathrm{La}_{2} \mathrm{O}_{3}$ Ceramics International 40 2014: pp. 15421-15438. https://dx. doi.org/10.1016/j.ceramint.2014.06.097

15. Jiang, D.F., Hong, C., Zhong, M.L., Alkhayat, M. Fabrication of Nano-TiCp Reinforced Inconel 625 Composite Coatings by Partial Dissolution of Micro-TiCp through Laser Cladding Energy Input Control Surface \& Coatings Technology 249 2014: pp. 125-131. https://dx. doi.org/10.1016/j.surfcoat.2014.03.057

16. Masanta, M., Ganesh, P., Kaul, R., Nath, A.K., Choudhury, A.R. Development of a Hard Nano-structured Multi-component Ceramic Coating by Laser Cladding Materials Science and Engineering A 508 2009: pp. $134-140$. https://dx. doi.org/10.1016/j.msea.2008.12.031
17. Ding, L., Hu, S.S. Effect of Nano-CeO 2 on Microstructure and Wear Resistance of Co-based Coatings Surface \& Coatings Technology 276 2015: pp. 565-572. https://dx. doi.org/10.1016/j.surfcoat.2015.06.014

18. Papageorgiou, D.G., Kinloch, I.A., $\quad$ Young, R.J. Mechanical Properties of Graphene and Graphene-based Nanocomposites Progress in Materials Science 90 2017: pp. $75-127$. https://dx. doi.org/10.1016/j.pmatsci.2017.07.004

19. Kim, K.W., Kim, J.H., Cho, S.H., Shin, K.W., Kim, S.H. Scalable High-performance Graphene Paper with Enhanced Electrical and Mechanical Properties Thin Solid Films 632 2017: pp. 50-54. https://dx. doi.org/10.1016/j.tsf.2017.04.039

20. Guo, G.F., Huang, H., Xue, F.H., Liu, C.J., Yu, H.T., Quan, X., Dong, X.L. Electrochemical Hydrogen Storage of the Graphene Sheets Prepared by DC Arc-discharge Method Surface \& Coatings Technology 228 2013: pp. S120-S125. https://dx. doi.org/10.1016/j.surfcoat.2012.07.016

21. Phiri, J., Gane, P., Maloney, T.C. General Overview of Graphene: Production, Properties and Application in Polymer Composites Materials Science and Engineering B 215 2017: pp. 9-28. https://dx. doi.org/10.1016/j.mseb.2016.10.004

22. Liu, Y.L., Xie, B., Zhang, Z., Zheng, Q.S., Xu, Z.P. Mechanical Properties of Graphene Papers Journal of the Mechanics and Physics of Solids 60 2012: pp. 591-605. https://dx. doi.org/10.1016/j.jmps.2012.01.002

23. Ma, C.,Wang, C.S. Influence of Graphite/Ni on Microstructure and Properties of Laser Clad Ni-based Alloy Coatings Chinese Journal of Laser 40 (5) 2013: pp. $08030031-08030036$. https://dx. doi.org/10.3788/j.cj1.201340.0803003 